\title{
NFATc1/aA: The other Face of NFAT Factors in Lymphocytes
}

\author{
Edgar Serfling ${ }^{*}$, Andris Avots, Stefan Klein-Hessling, Ronald Rudolf, Martin Vaeth and Friederike Berberich-Siebelt
}

\begin{abstract}
In effector T and B cells immune receptor signals induce within minutes a rise of intracellular $\mathrm{Ca}^{++}$, the activation of the phosphatase calcineurin and the translocation of NFAT transcription factors from cytosol to nucleus. In addition to this first wave of NFAT activation, in a second step the occurrence of NFATC1/aA, a short isoform of NFATc1, is strongly induced. Upon primary stimulation of lymphocytes the induction of NFATc1/aA takes place during the G1 phase of cell cycle. Due to an auto-regulatory feedback circuit high levels of NFATc1/aA are kept constant during persistent immune receptor stimulation. Contrary to NFATC2 and further NFATC proteins which dampen lymphocyte proliferation, induce anergy and enhance activation induced cell death (AICD), NFATc1/aA supports antigenmediated proliferation and protects lymphocytes against rapid AICD. Whereas high concentrations of NFATc1/aA can also lead to apoptosis, in collaboration with NF-KB-inducing co-stimulatory signals they support the survival of mature lymphocytes in late phases after their activation. However, if dysregulated, NFATc1/aA appears to contribute to lymphoma genesis and - as we assume - to further disorders of the lymphoid system. While the molecular details of NFATC1/aA action and its contribution to lymphoid disorders have to be investigated, NFATC1/aA differs in its generation and function markedly from all the other NFAT proteins which are expressed in lymphoid cells. Therefore, it represents a prime target for causal therapies of immune disorders in future.
\end{abstract}

Keywords: Activation induced cell death/AICD, Anergy, Apoptosis, Calcineurin, NFATc, NFATc1/aA, NF-kB, Proliferation

\section{NFAT Factors ${ }^{a}$}

The five members of the family of NFAT transcription factors are characterized by an evolutionary conserved DNA binding domain of approximately 300 amino acid (aa) residues. This domain forms a three dimensional structure similar to the DNA binding domain of Rel/NF$\mathrm{\kappa B}$ factors and, therefore, was designated as Rel Similarity Domain (RSD) or Rel Homology Domain (RHD)[1-3]. While the most distantly related NFAT5 shares $41-45 \%$ sequence similarity in its RSD with those of genuine NFATc factors NFATc1, c2, c3 and c4, the latter exhibit 68-75\% sequence homology between their RSDs [4]. The DNA core motif for the DNA binding of NFAT factors, $\mathrm{A} / \mathrm{T}$ GGAAA, resembles one half-site of $\kappa \mathrm{B}$ motif of NF$\kappa B$ factors, and there is a subset of $\kappa B$ binding motifs to which NFAT factors can also bind $[5,6]$. This was shown

\footnotetext{
* Correspondence: serfling.e@mail.uni-wuerzburg.de

Department of Molecular Pathology, Institute of Pathology, University of Würzburg, Josef-Schneider-Str 2, D-97080 Würzburg, Germany
}

at the molecular level for the binding of NFATc2 homodimers to the $\mathrm{\kappa B}$ motifs within the HIV LTR and the Il8 promoter which share the core motif of NFAT binding sites $[7,8]$. Since NFAT and NF-kB proteins contact identical nucleotides, it is unlikely that both factors can bind at the same time to the same motif. Instead, they appear to compete for DNA binding. This seems to depend on the cellular concentration of both types of factors and other parameters, such as the level of co-factors, as AP1 , which affects the binding of NFATs to DNA.

Due to the control by the $\mathrm{Ca}^{++} /$calmodulin-dependent Ser/Thr-protein phosphatase calcineurin $(\mathrm{CN}$; also known as PP2B) [1-3], the four genuine NFATc proteins constitute an own family of transcription factors with individual properties. Although they were described first for human Jurkat leukemic T cells [9] and murine EL-4 thymoma cells [10], they are not only expressed in lymphocytes but also in numerous other cells of the hematopoietic system, and also in cardiomyocytes, muscle, bone and brain cells. While in numerous studies 
the function of NFAT factors has been investigated in these tissues, in greatest detail the expression and function of individual NFATc proteins (including their isoforms) has been analysed in lymphoid cells [1-3].

In lymphocytes the three NFATc proteins NFATc1 (also known as NFAT2 or NFATc), c2 (NFAT1 or NFATp) and c3 (NFAT4 or NFATx) are expressed. Inactivation of individual $\mathrm{Nfatc}$ genes in mice revealed first indications for a functional dichotomy between the three proteins. Whereas due to defects in differentiation of embryonic heart, inactivation of the Nfatcl gene led to the early death of mouse embryos around day 14/15 upon gestation $[11,12], \mathrm{Nfatc2}^{-/-}$mice were born at the normal Mendelian ratio and did not show any abnormalities within the first weeks upon birth [13-15]. However, with age $\mathrm{Nfatc2^{-/- }}$ mice developed a hyper proliferative syndrome and elevated primary and secondary immune responses. Due to delayed apoptosis, $\mathrm{Natc}^{-/-}$mice of 6 months and older harbour at least twofold more peripheral lymphocytes suggesting a suppressive role for NFATc2 in the generation of effector lymphocytes $[13,14,16]$. Several properties of $\mathrm{Nfatc2}^{-/-}$mice were found to be markedly enhanced in mice double-deficient for NFATc2 and c3 [17]. Those mice showed a hyper proliferation of peripheral $\mathrm{T}$ and $\mathrm{B}$ cells leading to massive splenomegaly, a tendency to generate Th2 cells and, thereby, an enormous increase in production of Th2-type lymphokines [18]. In addition, lymphocytes double-deficient for NFATc2 and c3 show a strong decrease in Fas ligand expression and resistance to apoptosis $[17,19] . \mathrm{Nfatc}^{-/-}$mice, on the other hand, showed a $50 \%$ reduction in number of peripheral $\mathrm{T}$ lymphocytes which might be due to an increase in apoptosis rate. On the other hand, no obvious defects were observed in lymphokine (IL-2, IL-4 and IFN $\gamma$ ) production, and a slight decrease was detected in generation of single positive (SP) $\mathrm{CD}_{4}^{+}$and $\mathrm{CD}^{+}$thymocytes [20]. When conditionally inactivated in early double-negative (DN) thymocytes (in $N f a t c 3^{f l / f l}+l c k$-Cre mice), obvious defects were detected at the level of DN3 and double-positive (DP) thymocytes stages implying a role for NFATc3 in $\beta$ selection and positive selection of thymocytes [21].

Contrary to peripheral lymphocytes from NFATc2 and c3-deficient mice, $\mathrm{Nfatc1}^{-1-}$ lymphocytes from mice generated by complementation of $\mathrm{Rag}^{-/-}$blastocytes with $\mathrm{Nfatcl}^{-1-}$ embryonic stem cells showed a marked decrease in proliferation upon immune receptor stimulation $[22,23]$. This became obvious upon challenging $N$ fatc1 $^{-/-} \mathrm{T}$ cells with $\alpha \mathrm{CD} 3(+\alpha \mathrm{CD} 28)$, concanavalin $\mathrm{A}$ or PMA + ionomycin, while no difference in their IL-2 synthesis was detected [22]. In distinct contrast to NFATc2 + c3-double-deficient T cells, $\mathrm{Nfatc1}^{-/}$effector $\mathrm{T}$ cells produced markedly less - and not more - IL-4 (and IL-6) upon $\alpha \mathrm{CD} 3$ stimulation than T cells from wild type mice [22,23], and $\alpha \operatorname{IgM}$ stimulation revealed a decrease in BCR-mediated proliferation capacity of $\mathrm{Nfatc1}^{-/-}$ splenic B cells [22]. Similar results were observed upon conditional ablation of NFATc1 in B cells [24]. While in such $\mathrm{Nfatc}^{\mathrm{fl} / \mathrm{fl}}+\mathrm{mb1}$-Cre (or Cd23-Cre) mice, splenic B cell development appeared to be normal, in agreement with earlier observations [25] a 5-10 fold reduction in peritoneal B1a cells was observed. In addition to their low proliferation rate upon BCR stimulation, $\mathrm{Nfatc1}^{-/-}$splenic $B$ cells showed a decrease in their capacity to stimulate $T$ cells and an increase in AICD and IL-10 production. Moreover, a mild clinical course of Experimental Autoimmune Encephalomyelitis (EAE) was observed for $N f a t c f^{\ell l f l}+m b 1$-Cre mice. Several of these defects appeared to be due to the diminished $\mathrm{Ca}^{++}$flux in $\mathrm{Nfatcl}^{-1-}$ B cells whose proliferation is controlled by persistent $\mathrm{Ca}^{++} / \mathrm{CN}$ signals [24].

\section{The $\mathrm{Ca}^{++} /$calcineurin-mediated induction of NFATs in lymphocytes}

NFATc factors differ from most other transcription factors by their strict dependency on $\mathrm{Ca}^{++}$signals and $\mathrm{CN}$ activity [26] which induce the nuclear translocation and, thereby, activation of NFATc proteins. In the cytosol of effector lymphocytes and of most $\mathrm{T}$ and $\mathrm{B}$ cell lines, NFATc proteins are heavily phosphorylated and appear to be in complexes with the non-coding RNA NRON (Nonconding [RNA] repressor of NFAT) [27]. NRON creates a platform for larger RNP complexes [28] containing, in addition to NFAT, the three NFAT kinases casein kinase 1 (CK1), glycogen synthase kinase 3 (GSK3) and dual specificity tyrosine phosphorylation regulated kinase (DYRK), and calmodulin with further proteins [29].

Within minutes, immune receptor triggering leads to a rise in free intracellular $\mathrm{Ca}^{++}$by releasing $\mathrm{Ca}^{++}$from endoplasmic reticulum (ER) stores and, in particular, the influx of extracellular $\mathrm{Ca}^{++}$through calcium-releaseactivated calcium (CRAC) channels. The details of this so-called store-operated calcium entry (SOCE) have been summarized in several comprehensive reviews to which we want to refer here [30-32]. Elevated free $\mathrm{Ca}^{++}$level results in the binding of $\mathrm{Ca}^{++}$to calmodulin followed by the binding of $\mathrm{Ca}^{++} /$calmodulin to $\mathrm{CN}$ which interacts through two "docking" motifs with NFATc proteins [33] (Figure 1). As a result of dephosphorylation of 13 aa residues within the regulatory region of NFATc2 [34], the nuclear localization signal of NFATc2 appears to be exposed followed by the binding of nuclear import factors [29] and rapid nuclear translocation. While the details of this process have yet to be elucidated, all three NFATc factors expressed in lymphocytes appear to be induced and translocated into the nucleus of lymphocytes in a similar way. 


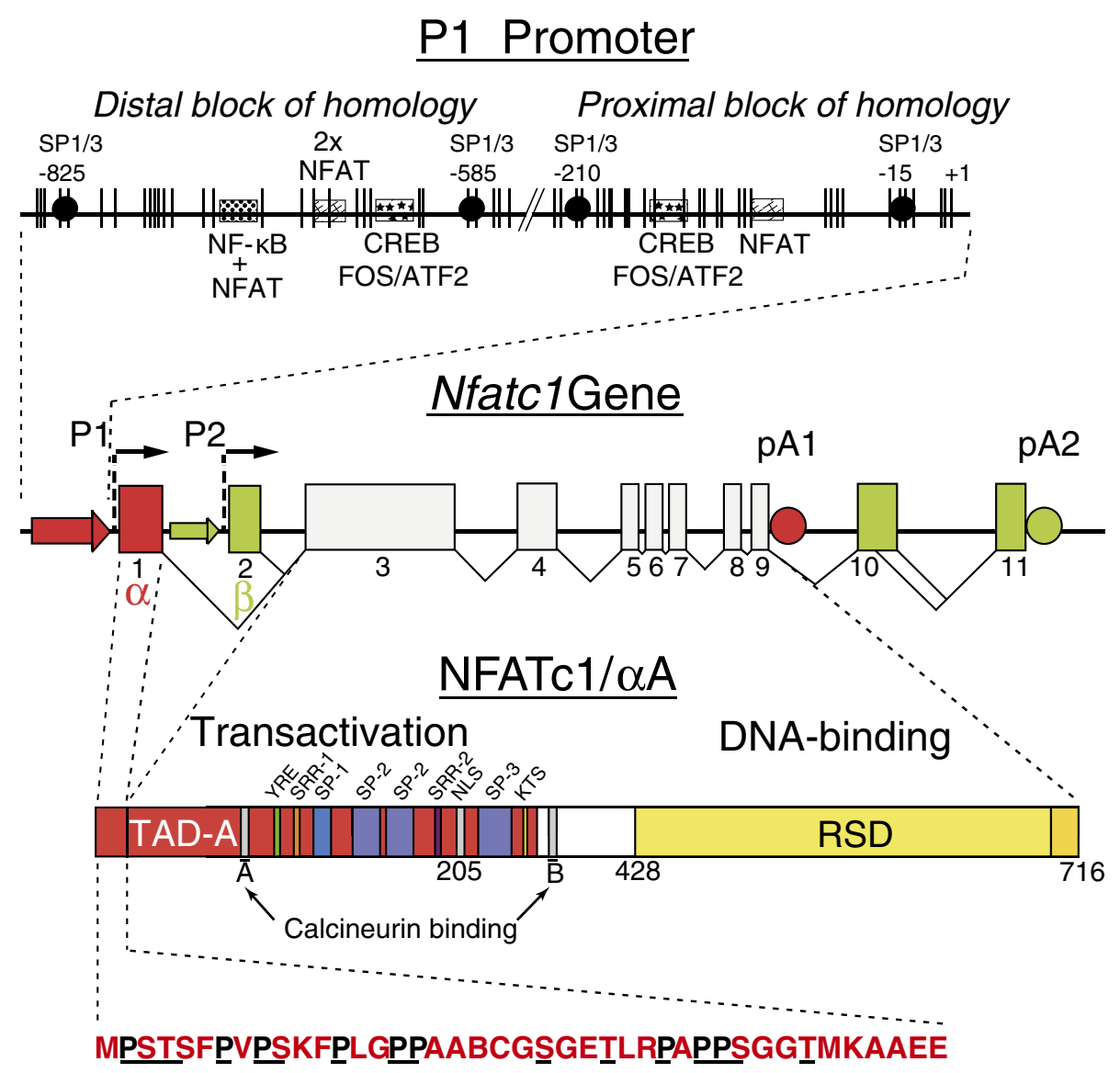

Figure 1 Scheme of the mouse Nfatc1 gene, its inducible promoter P1 (above) and the inducible short isoform NFATc1/aA (below) (modified according to refs. $[35,44,49,50,96])$. In the promoter sequence, vertical dashes indicate CpG residues. Binding sites for transcription factors are shown as filled circles (for Sp1/Sp3 binding) or as boxes for the binding of various other factors. The murine Nfatc1 gene spans approximately $110 \mathrm{~kb}$ DNA and is divided into 11 exons. Its expression is directed by two promoters, P1 and P2, and two poly A addition sites, $\mathrm{pA} 1$ and $\mathrm{pA} 2$. For the generation of NFATc1/aA RNA (encoding the a-peptide), the induction of P1 promoter results in the transcription of exon 1, splicing to exon 3 and poly A addition at the poly A site PA1. RNAs encoding the $\beta$-isoforms (with the $\beta$-peptide encoded by exon 2 ) are directed by promoter 2. The sequence of the $\mathrm{N}$-terminal a-peptide from NFATc1/aA is given below. For NFATc1/aA, the Rel Similarity Domain, RSD, and transactivation domain, TAD-A, are indicated. In analogy to other NFATc factors (see Refs. [1-3]), two sites A and B for the binding of calcineurin, a nuclear localization signal, NLS, and several Ser-rich motifs that are phosphorylated, are also indicated. Below NFATc1/aA, the aa sequence of $\mathrm{N}$-terminal a-peptide is shown in which all Pro and Ser/Thr residues are underlined.

\section{The transcriptional induction and auto-regulation of NFATc1 in lymphocytes}

In effector $\mathrm{T}$ and $\mathrm{B}$ lymphocytes immune receptor signals exert a secondary effect on NFAT activation, namely the strong induction of Nfatc1 expression. Contrary to the Nfatc2 gene which is constitutively expressed in peripheral effector lymphocytes, the transcription of the Nfatc1 gene is strongly induced upon stimulation in peripheral $\mathrm{T}$ and $\mathrm{B}$ cells. This results in the predominant synthesis of the short NFATc1/ $\alpha$ A isoform which spans 711 aa in mouse [35]. NFATc1/ $\alpha$ A differs from the longer NFATc proteins by its short C-terminal peptide (Figure 1 and Table 1). Thereby, it lacks a second transactivation/repressor domain which has been described for the longer NFATc1 isoforms C [36] (spanning 925
[NFATc $1 / \beta C$ ] and 939 aa [NFATc $1 / \alpha C$ ], respectively) and NFATc2 [37]. This domain harbours two highly conserved sumoylation motifs, and sumoylation of these motifs in NFATc1/C exerts a "dampening" effect on IL-2 production [38]. In addition, NFATc1/ $\alpha \mathrm{A}$ whose generation is directed by the inducible P1 promoter (Figure 1) differs from the NFATc1 $\beta$ isoforms and NFATc2 by an unusual $\mathrm{N}$-terminal peptide - the so-called $\alpha$-peptide. The $\alpha$-peptide spans 42 aa containing 9 Pro and 8 Ser + Thr residues in murine NFATc1/ $\alpha$ A (Figure 1), compared to 1 Pro and 2 Ser + Thr residues in the 28 aa long $N$-terminal $\beta$ peptide of NFATc $1 / \beta$ proteins. When expressed in EL-4 cells, NFATc1/ $\alpha$ A shows a half-life between $2-4 \mathrm{~h}$, whereas NFATc1/ $\beta \mathrm{A}$ appears to be more stable, in particular upon stimulation of cells by TPA 
Table 1 Selected properties of individual murine NFATc proteins expressed in lymphoid cells

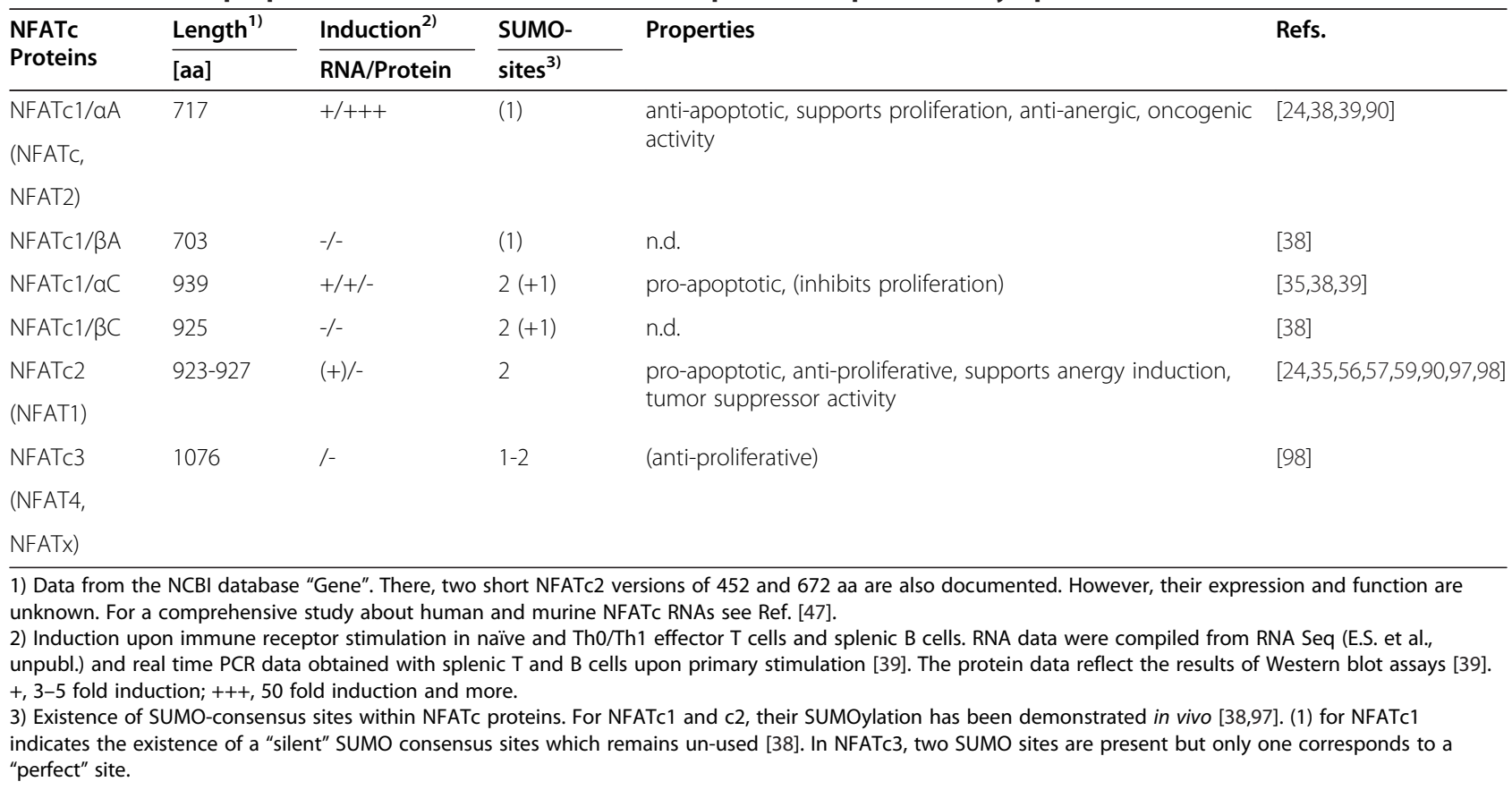

and ionomycin. And when fused to an estrogen receptor protein, the $\beta$-, but not the $\alpha$-peptide is able to extend the half-life of the relatively unstable receptor protein in 293 HEK cells [39].

NFATc $1 / \alpha \mathrm{A}$ is predominantly induced in Th 0 and Th1 effector cells, whereas under conditions of $\mathrm{T}$ cell anergy, in regulatory T cells (Treg) and in Th9 and Th17 its induction is suppressed [39]. The suppression in Treg appears to be due to the binding of Foxp3, the cell lineage specification factor of Treg [40], to the inducible Nfatc1 P1 promoter [41]. In conventional $\mathrm{CD} 4^{+} \mathrm{T}$ cells the induction of NFATc1/ $\alpha$ A can be suppressed by ICER, an inhibitory short isoform of CREM, which is induced by high cAMP levels. Treg contain high levels of cAMP [42], and by direct contacts they elevate cAMP levels in conventional effector $\mathrm{T}$ cells. Thereby, ICER is translocated into the nuclei of effector $\mathrm{T}$ cells and binds to the two cAMP responsive elements (CRE) within the inducible Nfatc1 P1 promoter [43].

In peripheral $\mathrm{T}$ and $\mathrm{B}$ cells, NFATc $1 / \alpha \mathrm{A}$ is the most prominent NFATc1 protein upon immune receptor stimulation. For the full induction of NFATc $1 / \alpha$ A protein in primary $\mathrm{T}$ and $\mathrm{B}$ cells more than $24 \mathrm{~h}$ activation through immune receptors are necessary, whereas upon secondary stimulation of $\mathrm{T}$ cells, NFATc $1 / \alpha \mathrm{A}$ is fully induced within a few hours $[24,36,44]$. Triggering of costimulatory receptors, such as ICOS in T cells [45], enhances the immune receptor-mediated induction of NFATc1/ $\alpha$ A. Since NFATc1/ $\alpha$ A is also strongly induced in T cells double-deficient for NFATc2 and c3 [39], the induction (and maintenance?) of high NFATc1 levels does not seem to depend on NFATc factors other than NFATc1 (as on NFATc2, as previously reported [46]). The identification of Rcan1 and calcineurin $A \beta / P p p 3 c b$ genes as NFATc1 targets in splenic B cells [24] suggests a regulatory circuit which guarantees persistent high expression of NFATc1/ $\alpha$ A in peripheral lymphocytes upon antigen challenging by auto-regulation.

The murine and human Nfatc1 genes span approximately 110 and $140 \mathrm{~kb}$ DNA, respectively, and are divided into 11 exons (Figure 1) (see also Ref. [47] for a detailed description of human and murine NFATc genes). The inducible transcription of NFATc $1 / \alpha \mathrm{A}$ is directed by the promoter P1 located in front of exon 1. P1 spans approximately $800 \mathrm{bp}$ which are highly conserved between mouse and human. Similar to the promoter P2 located in front of exon 2, the $\mathrm{P} 1$ promoter corresponds to a CpG methylation island and forms a DNase I hypersensitive chromatin site in $\mathrm{T}$ cells [35]. In addition, the chromatin of the P1 promoter bears a number of epigenetic chromatin marks, such as H3K4me3 as a typical sign of active eukaryotic promoters [48]. In human Hodgkin's lymphoma cell lines in which the NFATC1 gene is suppressed all $\mathrm{CPG}$ residues of P1 were found to be fully methylated, whereas in Jurkat $\mathrm{T}$ cells they are demethylated [49].

The P1 promoter can be divided into a proximal and distal block of homology, each spanning approximately 300 bp DNA. Both DNA blocks contain binding sites for NFAT factors, and in ChIP assays using EL-4 T cells it has been shown that they are bound by NFATs in vivo [39]. The NFAT binding sites within the distal block 
form a direct repeat of the NFAT core motif TGGAAA and bind NFAT factors with high affinity in EMSAs in vitro [35]. Upstream of these repeats, a composite NF$\kappa B / N F A T$ motif is located to which NF- $\kappa B$ factors were bound in EMSAs, but which could also allow the binding of NFAT homo-dimers. In addition, the P1 promoter contains two CRE-like sequence motifs located in the proximal and distal block of homology. They share 100\% sequence homology between mouse and man and were bound by CREB, Fos and ATF proteins in EMSAs [50]. The binding of CREB might be responsible for the poor transcriptional activity of the P1 promoter upon $\alpha \mathrm{CD} 3 /$ CD28 or TPA and ionomycin stimulation in T cells and the stimulatory effect of cAMP signals on P1 activity which, on the other hand, do not exert a positive but suppressive effect on the induction of the chromosomal Nfatc1 gene in T cells [35]. Whereas fusion of P1 to $5 \mathrm{~kb}$ upstream DNA did not result in a marked increase of its activity in transient transfections, fusion to a $1 \mathrm{~kb}$ DNA stretch from intron 1 of $N f a t c 1$ gene resulted in a 3-4 fold increase in P1 activity but did not change its inducibility [35]. However, when a DNase I-sensitive site from the last intron of the gene [51] was cloned downstream of a luciferase reporter gene whose expression was directed by P1, a 10-20 fold increase in P1-directed luciferase induction was detected (S. K.-H., unpubl. data).

In addition to P1 promoter activity, the generation of stable NFATc1/ $\alpha$ A RNAs needs poly A addition at the proximal poly A site A1 near the end of exon 9 (Figure 1). For the human NFATC1 gene, in transfection assays the pA1 site appeared as a "weaker" site than the distal NFATC1 pA2 site or the proximal poly A site from the Ig $\mu$ heavy chain gene [44]. From these and further experiments we concluded that in naïve and resting peripheral lymphocytes in which the longer NFATc1 isoforms are predominantly formed the proximal pA1 site remains unrecognized resulting in the generation of long NFATc1 RNAs. Due to the massive increase in splice/polyadenylation factors in activated $\mathrm{T}$ cells [52] in these cells the pA1 site becomes bound by polyadenylation factors and, thereby, functionally active [44]. Surprisingly, the pA1 sites of NFATc1 genes are not conserved between human and mouse leading to the synthesis of a $4.5 \mathrm{~kb}$ long NFATc1/ $\alpha$ A RNA in mouse lymphocytes, compared to that of $3 \mathrm{~kb}$ in human T cells (Ref. [44] and unpubl. data).

\section{NFATc1/aA is not induced in anergic lymphocytes}

The immune system does not only defend the organism against invading (micro-) organisms but also has to tolerate self-antigens to avoid auto immune diseases. In thymus, the majority of auto-reactive thymocytes are eliminated by the negative selection of DP thymocytes [53]. In addition to this central tolerance mechanism, in periphery the immune system is able to prevent unwanted immune reactions by rendering effector $\mathrm{T}$ and $\mathrm{B}$ cells unresponsive, or by eliminating auto-reactive lymphocytes. Several peripheral tolerance mechanisms can be distinguished, such as the generation of clonal anergy, adaptive tolerance [54], and the suppression of conventional $\mathrm{CD} 4^{+} \mathrm{T}$ cells (and B cells) by Treg [55]. While peripheral tolerance mechanisms have been studied in numerous experimental settings [54], we will focus here on experiments in which NFAT factors have been investigated.

Treatment of $\mathrm{T}$ cells for $16 \mathrm{~h}$ or more with ionomycin diminishes their subsequent induction by TCR signalling without inducing apoptosis. This leads to a strongly reduced RNA synthesis of lymphokines IL-2, IFN $\gamma$, TNF $\alpha$ and GM-CSF upon secondary stimulation [56], a typical sign of $\mathrm{T}$ cell anergy. When the gene expression profiles of anergic Th1 cells (clone D5) were determined a dramatic change in gene expression was detected. By using DNA microarrays, approximately 5 fold less genes were identified than after (full) activation with PMA and ionomycin which had changed their expression 3 fold. Among those 200 genes about $1 / 3$ was also detected in primary Th1 cells, including several genes encoding E3 ubiquitin ligases and proteases, such as Itch, Cbl-b and Grail [56,57]. Remarkably, in $\mathrm{Nfatc2}^{-/-} \mathrm{T}$ cells which are more resistant to anergy induction than wild type $\mathrm{T}$ cells, the expression of approximately 35 genes - including E3 ligase genes - was reduced implying a specific role for NFATc2 in anergy induction. Under anergic conditions two prominent signalling proteins of TCR signalling, PLC $\gamma 1$ and PKC- $\theta$ became ubiquitinated by $\mathrm{Ca}^{++}$signals and degraded [57]. Those and further findings suggested that under ionomycin-mediated anergic conditions NFATc2 only - but not AP-1 (or NF-kB and, probably, further "stimulating" factors, such as NFATc1/ $\alpha \mathrm{A}$ ) - is induced and binds to a subset of NFAT target genes, thereby stimulating the transcription of "anergy genes". Within the promoters of Rnf128 (encoding Grail) and caspase 3 genes (a further anergy-inducing gene) composite NF- $\kappa$ B/NFAT sites were detected to which NFATc2 homo-dimers were predominantly bound under anergic conditions. This led to the conclusion that the expression of a subset of anergy-inducing genes is controlled by NFATc2 homo-dimers [58]. NFATc2 was also shown to control B cell anergy (or adaptive tolerance) in MD4ML5 mice (expressing a HEL-specific BCR and transgenic HEL) [59] which are widely used to study B cell tolerance induction in vivo [60].

These findings suggest that NFATc factors in general exert a positive effect on E3 ubiquitin ligase expression and anergy induction [61]. However, published results and own experimental data suggest that NFATc1/ $\alpha$ A plays an opposite role in anergy induction. In own experiments, the BCR-mediated induction of NFATc1/ $\alpha$ A was found to be strongly impaired in anergic B cells from MD4ML5 mice 
(D.A.T. Pham, unpubl. results). When the Rnf128 gene was inactivated in mice the expression of NFATc1 was found to be strongly enhanced upon $\alpha \mathrm{CD} 3$ stimulation in naïve $\mathrm{CD} 4^{+} \mathrm{T}$ cells and Treg [62], and in an oral tolerance model the nuclear appearance and, therefore, induction of NFATc1 was suppressed in $\mathrm{CD} 4{ }^{+} \mathrm{T}$ cells upon activation through their TCR and CD4 molecules [63]. Taken together, these and further data strongly suggest that contrary to NFATc2 (and, probably, the longer, non-induced NFATc1 isoforms) the inducible NFATc1/ $\alpha$ A does not facilitate $\mathrm{T}$ and $\mathrm{B}$ cell anergy, but contributes to the optimal function of the immune system.

\section{NFATc1/aA induction is suppressed in regulatory T cells}

Regulatory $\mathrm{T}$ cells (Treg) are generated in thymus as socalled naturally occurring regulatory $\mathrm{T}$ cells, $\mathrm{nTreg}$, and in periphery as inducible regulatory $\mathrm{T}$ cells, iTreg. Both types of Treg are characterized by the expression of Foxp3, the constitutive expression of CD25 and the property to suppress the effector function of immune cells. Earlier work suggested an important role for $\mathrm{Ca}^{++}$ signals in the generation of nTreg [64]. It was also speculated that by binding near to NFAT sites, Foxp3 suppresses NFAT activity and lymphokine promoters [65].

This view found experimental support by studies on the interplay between Foxp2/3 and NFATc2. Determination of crystal structures of NFATc2-RSD and Foxp2-FKH (forkhead) domains formed with the distal NFAT site of the Il 2 promoter (the ARRE2 or $\mathrm{Pu}-\mathrm{b}_{\mathrm{d}}$ motif) suggested that Foxp3 could replace AP-1 in hetero-complexes formed with NFATc2 at the Il2 promoter [66]. However, novel investigations on the interaction of FKH domain from Foxp3 with NFATc2's RSD and $\mathrm{Pu}-\mathrm{b}_{\mathrm{d}}$ show that the structure of Foxp3's FKH differs from that of FKH domain from Foxp2 [67]. These complexes consist of two RSD, four FKH domains and two DNA sites which were held together by one "domain swapped" FKH domain dimer. At Pu-b $\mathrm{b}_{\mathrm{d}}$, the FKH domain dimers contact in trans two different cognate Foxp3 binding sites which overlap. Thereby, the FKH domain of Foxp3 bridges two DNA molecules by binding to two individual Foxp3 sites in solution and brings them together. Concerning the interaction with NFATc2's RSD, there is a larger interface between the RSD and Foxp3's FKH domain than with that from Foxp2 suggesting that Foxp3 "fits better" to NFATc2 than Foxp2 [67].

While these structural analyses suggested that Foxp3 and NFATc2 could form heteromeric complexes in Treg and control their regulatory function (as proposed in Ref. [66]), they did not show that such complexes really exist in nTreg or iTreg in vivo. On the basis of X-ray crystallography, mutations were introduced into the FKH domain of Foxp3 which interfere with the interaction of FKH to the RSD of NFATc2 [66]. Infections of mouse
$\mathrm{CD} 4^{+} \mathrm{T}$ cells with retroviruses expressing such mutant Foxp3 proteins led to conspicuous defects in Foxp3 and Treg function. All mutations within Foxp3's FKH which impaired the interaction with NFATc2 also impaired the ability of Foxp3 to suppress Il2 expression, and they impaired the expression of CD25, GITR, CD103, and, in particular, of CTLA4 which are all positively regulated by Foxp3 in Treg. Moreover, in a mouse model of autoimmune diabetes (the BDC2.5/NOD TCR tg mice [68]) co-transfer of $\mathrm{CD}^{+} \mathrm{T}$ cells expressing Foxp3 mutants were unable to suppress diabetes induction, whereas cells expressing wild type Foxp3 were able to suppress [66].

Earlier analyses of NFATc2 and c3-deficient mice indicated that the lack of both NFATc factors in mice did neither affect the generation of nTreg nor their function to suppress conventional $\mathrm{CD}^{+} \mathrm{T}$ cells. Instead, these assays suggested an intrinsic role for NFATc2 and c3 in $\mathrm{CD} 4^{+}$responder $\mathrm{T}$ cells to become suppressed by nTreg [69]. These data and those discussed above prompted us to investigate the role of NFATc1 in Treg by studying mice in which NFATc1 was conditionally deleted in T cells [70]. However, as in $N f a t c 2^{-/-} \mathrm{C3}^{-/-} \mathrm{T}$ cells, no effect of NFATc1-deficiency was detected on nTreg formation and function in Nfatc $1^{f l f l} \times C d 4-C r e$ mice. The same was observed for $\mathrm{T}$ cells deficient for NFATc1 and $\mathrm{c} 2$, and again for $\mathrm{T}$ cells from mice double-deficient for NFATc2 and c3. However, when the generation of iTreg was investigated upon primary $\alpha \mathrm{CD} 3+\mathrm{CD} 28$ stimulation by incubation with TGF $\beta+\mathrm{IL}-2$ in vitro and in vivo, a reduction in iTreg formation was detected for T cells deficient for either NFATc1 or $\mathrm{c} 2$, and this reduction was strongly accelerated for $\mathrm{T}$ cells double-deficient for NFATc1 and c2, or NFATc2 and c3. Similarly, the generation of iTreg was strongly diminished when NFATc1/ c2-double deficient $\mathrm{T}$ cells - instead of wild type T cells were co-transferred into lymphopenic mice to induce colitis (which is an approach to induce iTreg under inflammatory conditions [71]). In ChIP assays an increase in NFATc1 binding was detected upon TGF $\beta$ treatment of $\mathrm{CD}_{4}^{+} \mathrm{T}$ cells to the intronic CNS1 enhancer element of the Foxp3 gene whose activity was shown to be controlled by NFAT and Smad factors [72]. Foxp3 suppresses NFATc1 induction by binding to the P1 promoter and inhibits its activity [41]. In addition, Treg were shown to have a reduced $\mathrm{Ca}^{++}$flux [73], $\mathrm{CN}$ activity and, thereby, NFATc activation [74].

\section{NFATc1 suppresses the Activation Induced Cell Death (AICD) of lymphocytes}

Activation Induced Cell Death (AICD) is one route of apoptosis induction in lymphocytes which, when suppressed, contributes to cancerogenesis of lymphocytes and other cells [75]. NFATc1 and c2 exert contrary effects on AICD of peripheral B and T cells. Upon $\alpha$-IgM stimulation murine 
splenic $\mathrm{Nfatc1}^{-/-}$B cells show a higher apoptosis rate than wild type B cells, indicating an anti-apoptotic activity for NFATc1 and, particularly, for NFATc1/ $\alpha$ A which is predominantly expressed under these conditions in splenic B cells [24]. Under the same conditions $\mathrm{Nfatc2}^{-/-} \mathrm{B}$ cells were found to be resistant to apoptosis induction [24] supporting earlier work on the pro-apoptotic role of NFATc2 in BCRmediated apoptosis in human Burkitt's lymphoma B cells [76]. Similar results were observed for murine T cells indicating a dichotomy between NFATc1/ $\alpha$ A and NFATc2 in apoptosis induction [35]. The expression of numerous genes which are known to affect apoptosis are regulated by NFATc factors in lymphocytes. Such as the promoters/ enhancers of Fas ligand, CD40 ligand, PD-1, light and osteopontin genes [24,77-81], the promoter directing the expression of short isoform of caspase 8-inhibitor c-Flip in murine $\mathrm{T}$ cells [82] and several others. However, differences in NFATc1/ $\alpha$ A or NFATc2 binding to the promoters/enhancers of these genes have not been observed. Therefore, it remains to be shown how the apparent contrasting effect of various NFATc proteins on AICD of lymphocytes is reflected at the molecular level. The strong induction of NFATc1/ $\alpha A$ upon stimulation of $T$ and $B$ effector cells supports the speculation that high levels of NFATc1/ $\alpha$ A can protect against AICD whereas low levels are unable to do so. However, when (naïve) splenic B cells in which large amounts of NFATc1/ $\alpha$ A are generated upon BCR stimulation for 2 days ex vivo [24] are stimulated by $\alpha$-IgM for 3 days and longer, they die by AICD, unless they are rescued by $\alpha-C D 40$, LPS or CpG which all induce NF-kB factors. This suggests that in immune responses NFATc1/ $\alpha \mathrm{A}$ and NF- $\mathrm{kB}$ factors collaborate in the clonal expansion (and differentiation) of lymphocytes. At the end of an immune reaction, the majority of lymphocytes will undergo apoptosis when they bear an excess of NFATc factors, whereas those with an "optimal" ratio between NFATc1/ $\alpha$ A and NF-kBs will survive.

\section{NFATc1/aA as a putative oncogene which supports lymphomagenesis}

Similar to the control of apoptosis, NFATc factors appear to exert dual functions in the generation of lymphoid and other malignancies. Genome-wide mappings of common insertion sites (CIS) for oncogenic retroviruses revealed a preference of insertions into the murine $N f a t c 1$ and $c 3$ genes. Whereas in total 24 provirus insertions were detected for the Nfatc1 locus and 16 for the Nfatc3 locus, only two insertions located more than $30 \mathrm{~kb} 3$ ' from the Nfatc2 gene were detected, and no within or near the Nfatc4 gene [83-88]. For the Nfatc1 gene, all 24 proviral insertions were detected either around its promoter region or within (or very close to) intron 10, and a similar distribution of insertions sites was found for the Nfatc3 gene. In hematopoietic cells, several DNase I hypersensitive sites, and in Th1 and Th2 cells the H3K4me3 chromatin mark, a sign for active transcription, were mapped within intron 10 of the Nfatc1 gene [48,51]. These data suggest that oncogenic retroviruses insert into the transcriptionally active regions of $N f a t c 1$ gene to affect its expression.

The identification of common sites for retroviral integrations favours the $\mathrm{Nfatc1}$ and $\mathrm{Nfatc3}$ genes as putative oncogenes for the generation of lymphoid tumors. However, this does not exclude that the expression of human NFATC1 gene is switched off in classical Hodgkin's lymphoma cells in which BCR signalling is suppressed [49], and NFATc3 can function as a tumor-suppressor for retrovirus-induced $\mathrm{T}$ cell lymphomas [84]. Its pro-apoptotic activity favours, on the other hand, NFATc2 as a tumor suppressor, and it has been described as a suppressor of neoplastic changes in chondrogenesis [89].

Albeit not shown in lymphoid cells, the dual role of NFATc1/ $\alpha$ A and NFATc2 in oncogenesis has been demonstrated by ectopic expression (of constitutively active [ca] versions of) both factors in NIH 3 T3 cells [90]. While caNFATc2 led to cell cycle arrest and apoptosis, overexpression of caNFATc1/ $\alpha$ A led to an increase in proliferation and cell transformation. Moreover, lack of NFATc2 resulted in an elevated tumor formation induced by the tumor promoter methylcholanthrene. To a large part, the differences in oncogenic capacity between caNFATc1 and c2 could be attributed to the $\mathrm{C}$-terminal peptide of NFATc2, since removal of the 230 aa long C-terminal peptide from NFATc2 (including its SUMO sites) released its tumor suppressor phenotype and "converted" NFATc2 to a NFATc1/ $\alpha A$-like protein [90].

There are several reports on the de-regulation of $\mathrm{Ca}^{++} / \mathrm{CN}$ mediated induction of NFATc1 in human haematopoietic malignancies supporting the former finding on the "oncogenic nature" of NFATc1 (see refs. [91,92] for current reviews). For diffuse large B-cell lymphomas (DLBCL) [93] and pancreatic cancer cells [94] an NFATc1-directed up-regulation of the $M Y C$ gene has been described which appears to be due to the recruitment of histone acetylases to the $M Y C$ promoter [95]. This suggests that NFATc1 might also be involved in further human lymphomas in which c-Myc is overexpressed, such as in Burkitt's lymphomas.

\section{Conclusions}

The short NFATc1 protein NFATc1/ $\alpha$ A differs in its structure and function from numerous, if not all other NFAT proteins. NFATc1/ $\alpha$ A lacks a 250 aa residues long Cterminal peptide with two sumoylation motifs, it contains a specific N-terminal peptide with several Ser/Thr and Pro residues, and its synthesis is strongly enhanced in effector $\mathrm{T}$ and $\mathrm{B}$ cells by immune receptor signals. Several lines of evidence indicate that NFATc1/ $\alpha \mathrm{A}$ contributes - in 
collaboration with NF-kB factors - to the survival of effector lymphocytes. These properties favour NFATc1/ $\alpha \mathrm{A}$ as a target for treating disorders of the immune system.

\section{Endnotes}

${ }^{a}$ For simplicity we use here and in all our other publications the term "NFAT factors" for members of a family of transcription factors which share a number of specific properties, e.g. the induction by calcineurin which dephosphorylates an array of phosphorylated sites upon cell activation. We are aware that the term NFAT (Nuclear Factor of Activated T Cells) is misleading since these transcription factors are expressed in numerous other cell types as well, and the acronym NFAT indicates the term factor.

\begin{abstract}
Abbreviations
AICD, Activation Induced Cell Death; a-IgM, Antibody directed against the IgM B cell receptor; BCR, B Cell Receptor; CAMP, adenosine $3^{\prime}: 5^{\prime}$ cyclic monophosphate; ChIP, Chromatin Immunoprecipitation; CN, Calcineurin; CRE, CAMP Responsive Element; CREM, CAMP Response Modulator gene; CsA, Cyclosporin A; HEL, Hen Egg Lysozyme; ICER, the inducible CAMP early repressor; iTreg, Inducible regulatory T cells; NFAT, Nuclear factor of activated T cells; nTreg, Naturally occurring regulatory Tcells; PMA, Phorbol 12-myristate 13 acetate; TCR, T cell receptor; TPA, 12-O-tetradecanoyl phorbol-13-acetate.
\end{abstract}

\section{Competing interest}

The authors declare that that they have no competing interests.

\section{Authors' contribution}

ES wrote the draft of the manuscript which was discussed in detail, modified and corrected by AA, S K-H, RR, MV and F B-S. Figure 1 was made by RR. All authors read and approved the final manuscript.

\section{Acknowledgements}

The experimental work in our laboratory was supported by the Deutsche Forschungsgemeinschaft (Transregio TR52), the Wilhelm-Sander und Scheel foundations

\section{Funding}

This publication was funded by the German Research Foundation (DFG) and the University of Wuerzburg in the funding programme Open Access Publishing.

Received: 20 April 2012 Accepted: 19 June 2012

Published: 5 July 2012

\section{References}

1. Hogan PG, Chen L, Nardone J, Rao A: Transcriptional regulation by calcium, calcineurin, and NFAT. Genes Dev 2003, 17:2205-2232.

2. Crabtree $G R$, Olson EN: NFAT signaling: choreographing the social lives of cells. Cell 2002, 109(Suppl):S67-S79.

3. Serfling E, Berberich-Siebelt F, Chuvpilo S, Jankevics E, Klein-Hessling S, Twardzik T, Avots A: The role of NF-AT transcription factors in T cell activation and differentiation. Biochim Biophys Acta 2000, 1498:1-18.

4. Lopez-Rodriguez C, Aramburu J, Rakeman AS, Rao A: NFAT5, a constitutively nuclear NFAT protein that does not cooperate with Fos and Jun. Proc Natl Acad Sci USA 1999, 96:7214-7219.

5. McCaffrey PG, Jain J, Jamieson C, Sen R, Rao A: A T cell nuclear factor resembling NF-AT binds to an NF-kappa $B$ site and to the conserved lymphokine promoter sequence "cytokine-1". J Biol Chem 1992, 267:1864-1871.

6. Serfling E, Berberich-Siebelt F, Avots A, Chuvpilo S, Klein-Hessling S, Jha MK, Kondo E, Pagel P, Schulze-Luehrmann J, Palmetshofer A: NFAT and NF-kappaB factors-the distant relatives. Int J Biochem Cell Biol 2004, 36:1 166-1170.

7. Giffin MJ, Stroud JC, Bates DL, von Koenig KD, Hardin J, Chen L: Structure of NFAT1 bound as a dimer to the HIV-1 LTR kappa B element. Nat Struct Biol 2003, 10:800-806.
8. Jin L, Sliz P, Chen L, Macian F, Rao A, Hogan PG, Harrison SC: An asymmetric NFAT1 dimer on a pseudo-palindromic kappa B-like DNA site. Nat Struct Biol 2003, 10:807-811.

9. Shaw JP, Utz PJ, Durand DB, Toole JJ, Emmel EA, Crabtree GR: Identification of a putative regulator of early T cell activation genes. Science 1988, 241:202-205.

10. Serfling E, Barthelmas R, Pfeuffer I, Schenk B, Zarius S, Swoboda R, Mercurio F, Karin M: Ubiquitous and lymphocyte-specific factors are involved in the induction of the mouse interleukin 2 gene in $T$ lymphocytes. EMBO J 1989, 8:465-473.

11. de la Pompa JL, Timmerman LA, Takimoto H, Yoshida H, Elia AJ, Samper E, Potter J, Wakeham A, Marengere L, Langille BL, et al: Role of the NF-ATc transcription factor in morphogenesis of cardiac valves and septum. Nature 1998, 392:182-186.

12. Ranger AM, Grusby MJ, Hodge MR, Gravallese EM, de la Brousse FC, Hoey T, Mickanin C, Baldwin HS, Glimcher LH: The transcription factor NF-ATc is essential for cardiac valve formation. Nature 1998, 392:186-190.

13. Xanthoudakis S, Viola JP, Shaw KT, Luo C, Wallace JD, Bozza PT, Luk DC, Curran T, Rao A: An enhanced immune response in mice lacking the transcription factor NFAT1. Science 1996, 272:892-895.

14. Hodge MR, Ranger AM, Charles De La Brousse F, Hoey T, Grusby MJ, Glimcher LH: Hyperproliferation and dysregulation of IL-4 expression in NF-ATp-deficient mice. Immunity 1996, 4:397-405.

15. Schuh K, Kneitz B, Heyer J, Siebelt F, Fischer C, Jankevics E, Rude E, Schmitt E, Schimpl A, Serfling E: NF-ATp plays a prominent role in the transcriptional induction of Th2-type lymphokines. Immunol Lett 1997, 57:171-175.

16. Schuh K, Twardzik T, Kneitz B, Heyer J, Schimpl A, Serfling E: The interleukin 2 receptor alpha chain/CD25 promoter is a target for nuclear factor of activated T cells. J Exp Med 1998, 188:1369-1373.

17. Ranger AM, Oukka M, Rengarajan J, Glimcher LH: Inhibitory function of two NFAT family members in lymphoid homeostasis and Th2 development. Immunity 1998, 9:627-635.

18. Rengarajan J, Tang B, Glimcher LH: NFATc2 and NFATc3 regulate $T(H) 2$ differentiation and modulate TCR-responsiveness of naive $T(H)$ cells. Nat Immunol 2002, 3:48-54.

19. Rengarajan J, Mittelstadt PR, Mages HW, Gerth AJ, Kroczek RA, Ashwell JD, Glimcher LH: Sequential involvement of NFAT and Egr transcription factors in FasL regulation. Immunity 2000, 12:293-300.

20. Oukka M, Ho IC, de la Brousse FC, Hoey T, Grusby MJ, Glimcher LH: The transcription factor NFAT4 is involved in the generation and survival of T cells. Immunity 1998, 9:295-304.

21. Cante-Barrett $K$, Winslow MM, Crabtree GR: Selective role of NFATc3 in positive selection of thymocytes. J Immunol 2007, 179:103-110.

22. Yoshida H, Nishina $H$, Takimoto $H$, Marengere LE, Wakeham AC, Bouchard D, Kong YY, Ohteki T, Shahinian A, Bachmann M, et al: The transcription factor NF-ATc1 regulates lymphocyte proliferation and Th2 cytokine production. Immunity 1998, 8:115-124.

23. Ranger AM, Hodge MR, Gravallese EM, Oukka M, Davidson L, Alt FW, de la Brousse FC, Hoey T, Grusby M, Glimcher LH: Delayed lymphoid repopulation with defects in IL-4-driven responses produced by inactivation of NF-ATc. Immunity 1998, 8:125-134.

24. Bhattacharyya S, Deb J, Patra AK, Thuy Pham DA, Chen W, Vaeth M, Berberich-Siebelt F, Klein-Hessling S, Lamperti ED, Reifenberg K, et al: NFATc1 affects mouse splenic $B$ cell function by controlling the calcineurin--NFAT signaling network. J Exp Med 2011, 208:823-839.

25. Berland R, Wortis HH: Normal B-1a cell development requires B cell-intrinsic NFATc1 activity. Proc Natl Acad Sci USA 2003, 100:13459-13464.

26. Sieber M, Karanik M, Brandt C, Blex C, Podtschaske M, Erdmann F, Rost R

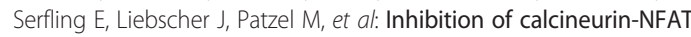
signaling by the pyrazolopyrimidine compound NCI3. Eur J Immunol 2007, 37:2617-2626.

27. Liu Z, Lee J, Krummey S, Lu W, Cai H, Lenardo MJ: The kinase LRRK2 is a regulator of the transcription factor NFAT that modulates the severity of inflammatory bowel disease. Nat Immunol 2011, 12:1063-1070.

28. Willingham AT, Orth AP, Batalov S, Peters EC, Wen BG, Aza-Blanc P, Hogenesch JB, Schultz PG: A strategy for probing the function of noncoding RNAs finds a repressor of NFAT. Science 2005, 309:1570-1573.

29. Sharma S, Findlay GM, Bandukwala HS, Oberdoerffer S, Baust B, Li Z, Schmidt V, Hogan PG, Sacks DB, Rao A: Dephosphorylation of the nuclear factor of activated T cells (NFAT) transcription factor is regulated by an RNA-protein scaffold complex. Proc Natl Acad Sci USA 2011, 108:11381-11386. 
30. Feske S: Calcium signalling in lymphocyte activation and disease. Nat Rev Immunol 2007, 7:690-702.

31. Hogan PG, Lewis RS, Rao A: Molecular basis of calcium signaling in lymphocytes: STIM and ORAI. Annu Rev Immunol 2010, 28:491-533.

32. Li H, Rao A, Hogan PG: Interaction of calcineurin with substrates and targeting proteins. Trends Cell Biol 2011, 21:91-103.

33. Rodriguez A, Roy J, Martinez-Martinez S, Lopez-Maderuelo MD, Nino-Moreno P, Orti L, Pantoja-Uceda D, Pineda-Lucena A, Cyert MS, Redondo $J$ M: A conserved docking surface on calcineurin mediates interaction with substrates and immunosuppressants. Mol Cell 2009, 33:616-626.

34. Okamura H, Aramburu J, Garcia-Rodriguez C, Viola JP, Raghavan A, Tahiliani M, Zhang X, Qin J, Hogan PG, Rao A: Concerted dephosphorylation of the transcription factor NFAT1 induces a conformational switch that regulates transcriptional activity. Mol Cell 2000, 6:539-550.

35. Chuvpilo S, Jankevics E, Tyrsin D, Akimzhanov A, Moroz D, Jha MK, Schulze-Luehrmann J, Santner-Nanan B, Feoktistova E, Konig T, et al: Autoregulation of NFATc1/aA expression facilitates effector T cells to escape from rapid apoptosis. Immunity 2002, 16:881-895.

36. Chuvpilo S, Avots A, Berberich-Siebelt F, Glockner J, Fischer C, Kerstan A Escher C, Inashkina I, Hlubek F, Jankevics E, et al: Multiple NF-ATc isoforms with individual transcriptional properties are synthesized in $\mathrm{T}$ lymphocytes. J Immunol 1999, 162:7294-7301.

37. Luo C, Burgeon E, Rao A: Mechanisms of transactivation by nuclear factor of activated T cells-1. J Exp Med 1996, 184:141-147.

38. Nayak A, Glöckner-Pagel J, Vaeth M, Schumann JE, Buttmann M, Bopp T, Schmitt E, Serfling E, Berberich-Siebelt F: Sumoylation of the transcription factor NFATc1 leads to its subnuclear relocalization and interleukin-2 repression by histone deacetylase. J Biol Chem 2009, 284:10935-10946.

39. Hock M, Vaeth M, Muhammad K, Rudolf R, Pusch T, Berberich-Siebelt F, Tyrsin D, Chuvpilo S, Avots A, Serfling E, Klein-Hessling S: The induction of NFATC1 in peripheral T and B lymphocytes, 2012. Submitted for publication.

40. Fontenot JD, Rudensky AY: A well adapted regulatory contrivance: regulatory $T$ cell development and the forkhead family transcription factor Foxp3. Nat Immunol 2005, 6:331-337.

41. Torgerson TR, Genin A, Chen C, Zhang M, Zhou B, Anover-Sombke S, Frank MB, Dozmorov I, Ocheltree E, Kulmala $P$, et al: FOXP3 inhibits activation-induced NFAT2 expression in T cells thereby limiting effector cytokine expression. J Immunol 2009, 183:907-915.

42. Bopp T, Becker C, Klein M, Klein-Hessling S, Palmetshofer A, Serfling E, Heib V, Becker M, Kubach J, Schmitt S, et al: Cyclic adenosine monophosphate is a key component of regulatory T cell-mediated suppression. J Exp Med 2007, 204:1303-1310.

43. Vaeth M, Gogishvili T, Bopp T, Klein M, Berberich-Siebelt F, Gattenloehner S, Avots A, Sparwasser T, Grebe N, Schmitt E, et al: Regulatory T cells facilitate the nuclear accumulation of inducible cAMP early repressor (ICER) and suppress nuclear factor of activated T cell c1 (NFATc1). Proc Natl Acad Sci USA 2011, 108:2480-2485.

44. Chuvpilo S, Zimmer M, Kerstan A, Glockner J, Avots A, Escher C, Fischer C, Inashkina I, Jankevics E, Berberich-Siebelt F, et al: Alternative polyadenylation events contribute to the induction of NF-ATc in effector T cells. Immunity 1999, 10:261-269.

45. Nurieva RI, Chuvpilo S, Wieder ED, Elkon KB, Locksley R, Serfling E, Dong C: A Costimulation-Initiated Signaling Pathway Regulates NFATc1 Transcription in T Lymphocytes. J Immunol 2007, 179:1096-1103.

46. Zhou B, Cron RQ, Wu B, Genin A, Wang Z, Liu S, Robson P, Baldwin HS: Regulation of the murine Nfatc1 gene by NFATc2. J Biol Chem 2002, 277:10704-10711.

47. Vihma H, Pruunsild P, Timmusk T: Alternative splicing and expression of human and mouse NFAT genes. Genomics 2008, 92:279-291.

48. Wei G, Wei L, Zhu J, Zang C, Hu-Li J, Yao Z, Cui K, Kanno Y, Roh TY, Watford WT, et al: Global mapping of H3K4me3 and H3K27me3 reveals specificity and plasticity in lineage fate determination of differentiating CD4+ T cells. Immunity 2009, 30:155-167.

49. Akimzhanov A, Krenacs L, Schlegel T, Klein-Hessling S, Bagdi E, Stelkovics E, Kondo E, Chuvpilo S, Wilke P, Avots A, et al: Epigenetic Changes and Suppression of the Nuclear Factor of Activated T Cell 1 (NFATC1) Promoter in Human Lymphomas with Defects in Immunoreceptor Signaling. Am J Pathol 2008, 172:215-224.

50. Serfling E, Chuvpilo S, Liu J, Hofer T, Palmetshofer A: NFATc1 autoregulation: a crucial step for cell-fate determination. Trends Immunol 2006, 27:461-469.
51. Bernstein BE, Stamatoyannopoulos JA, Costello JF, Ren B, Milosavljevic A, Meissner A, Kellis M, Marra MA, Beaudet AL, Ecker JR, et al: The NIH Roadmap Epigenomics Mapping Consortium. Nat Biotechnol 2010, 28:1045-1048.

52. Edwalds-Gilbert G, Veraldi KL, Milcarek C: Alternative poly(A) site selection in complex transcription units: means to an end? Nucleic Acids Res 1997, 25:2547-2561.

53. Kyewski B, Klein L: A central role for central tolerance. Annu Rev Immunol 2006, 24:571-606.

54. Schwartz RH: T cell anergy. Annu Rev Immunol 2003, 21:305-334.

55. Serfling E, Klein-Hessling S, Palmetshofer A, Bopp T, Stassen M, Schmitt E: NFAT transcription factors in control of peripheral T cell tolerance. Eur J Immunol 2006, 36:2837-2843.

56. Macian F, Garcia-Cozar F, Im SH, Horton HF, Byrne MC, Rao A: Transcriptional mechanisms underlying lymphocyte tolerance. Cell 2002, 109:719-731.

57. Heissmeyer V, Macian F, Im SH, Varma R, Feske S, Venuprasad K, Gu H, Liu YC, Dustin ML, Rao A: Calcineurin imposes T cell unresponsiveness through targeted proteolysis of signaling proteins. Nat Immunol 2004, 5:255-265.

58. Soto-Nieves N, Puga I, Abe BT, Bandyopadhyay S, Baine I, Rao A, Macian F: Transcriptional complexes formed by NFAT dimers regulate the induction of T cell tolerance. J Exp Med 2009, 206:867-876.

59. Barrington RA, Borde M, Rao A, Carroll MC: Involvement of NFAT1 in B cell self-tolerance. J Immunol 2006, 177:1510-1515

60. Healy JI, Dolmetsch RE, Timmerman LA, Cyster JG, Thomas ML, Crabtree GR, Lewis RS, Goodnow CC: Different nuclear signals are activated by the B cell receptor during positive versus negative signaling. Immunity 1997, 6:419-428.

61. Davis M, Ben-Neriah Y: Behind the scenes of anergy: a tale of three E3s. Nat Immunol 2004, 5:238-240.

62. Nurieva Rl, Zheng S, Jin W, Chung Y, Zhang Y, Martinez GJ, Reynolds JM, Wang SL, Lin X, Sun SC, et al: The E3 ubiquitin ligase GRAIL regulates T cell tolerance and regulatory $T$ cell function by mediating $T$ cell receptor-CD3 degradation. Immunity 2010, 32:670-680.

63. Asai K, Hachimura S, Kimura M, Toraya T, Yamashita M, Nakayama T, Kaminogawa S: T cell hyporesponsiveness induced by oral administration of ovalbumin is associated with impaired NFAT nuclear translocation and p27kip1 degradation. J Immunol 2002, 169:4723-4731.

64. Sakaguchi S, Sakaguchi N: Thymus and autoimmunity. Transplantation of the thymus from cyclosporin A-treated mice causes organ-specific autoimmune disease in athymic nude mice. J Exp Med 1988, 167:1479-1485.

65. Ziegler SF: FOXP3: of mice and men. Annu Rev Immunol 2006, 24:209-226

66. Wu Y, Borde M, Heissmeyer V, Feuerer M, Lapan AD, Stroud JC, Bates DL, Guo L, Han A, Ziegler SF, et al: FOXP3 Controls Regulatory T Cell Function through Cooperation with NFAT. Cell 2006, 126:375-387.

67. Bandukwala HS, Wu Y, Feuerer M, Chen Y, Barboza B, Ghosh S, Stroud JC, Benoist C, Mathis D, Rao A, Chen L: Structure of a domain-swapped FOXP3 dimer on DNA and its function in regulatory T cells. Immunity 2011, 34:479-491.

68. Katz JD, Benoist C, Mathis D: T helper cell subsets in insulin-dependent diabetes. Science 1995, 268:1185-1188.

69. Bopp T, Palmetshofer A, Serfling E, Heib V, Schmitt S, Richter C, Klein M, Schild $H$, Schmitt E, Stassen M: NFATc2 and NFATc3 transcription factors play a crucial role in suppression of CD4+ T lymphocytes by CD4+ CD25+ regulatory T cells. J Exp Med 2005, 201:181-187.

70. Vaeth M, Schließer U, Reißig S, Satoh K, Jonuleit H, Waisman A, Müller MR, Serfling E, Sawitzki B, Berberich-Siebelt F: The dependence on NFAT levels discriminates conventional T cells from Foxp3+ regulatory $T$ cells. In revision 2012.

71. Izcue A, Coombes $J$, Powrie F: Regulatory T cells suppress systemic and mucosal immune activation to control intestinal inflammation. Immunol Rev 2006, 212:256-271

72. Tone $Y$, Furuuchi K, Kojima $Y$, Tykocinski ML, Greene MI, Tone M: Smad3 and NFAT cooperate to induce Foxp3 expression through its enhancer. Nat Immunol 2008, 9:194-202.

73. Gavin MA, Clarke SR, Negrou E, Gallegos A, Rudensky A: Homeostasis and anergy of CD4(+)CD25(+) suppressor T cells in vivo. Nat Immunol 2002, 3:33-41. 
74. Sumpter TL, Payne KK, Wilkes DS: Regulation of the NFAT pathway discriminates $C D 4+C D 25+$ regulatory $T$ cells from $C D 4+C D 25$ - helper $T$ cells. J Leukoc Biol 2008, 83:708-717.

75. Hanahan D, Weinberg RA: The hallmarks of cancer. Cell 2000, 100:57-70

76. Kondo E, Harashima A, Takabatake T, Takahashi H, Matsuo Y, Yoshino T, Orita K, Akagi T: NF-ATc2 induces apoptosis in Burkitt's lymphoma cells through signaling via the B cell antigen receptor. Eur J Immunol 2003, 33:1-11.

77. Latinis KM, Norian LA, Eliason SL, Koretzky GA: Two NFAT transcription factor binding sites participate in the regulation of CD95 (Fas) ligand expression in activated human T cells. J Biol Chem 1997, 272:31427-31434.

78. Li-Weber M, Laur O, Krammer PH: Novel Egr/NF-AT composite sites mediate activation of the CD95 (APO-1/Fas) ligand promoter in response to T cell stimulation. Eur J Immunol 1999, 29:3017-3027.

79. Xiao S, Matsui K, Fine A, Zhu B, Marshak-Rothstein A, Widom RL, Ju ST: FasL promoter activation by IL-2 through SP1 and NFAT but not Egr-2 and Egr-3. Eur J Immunol 1999, 29:3456-3465.

80. Schubert LA, King G, Cron RQ, Lewis DB, Aruffo A, Hollenbaugh D: The human gp39 promoter. Two distinct nuclear factors of activated T cel protein-binding elements contribute independently to transcriptional activation. J Biol Chem 1995, 270:29624-29627.

81. Brunner M, Zhang M, Genin A, Ho IC, Cron RQ: A T-cell-specific CD154 transcriptional enhancer located just upstream of the promoter. Genes Immun 2008, 9:640-649.

82. Ueffing N, Schuster M, Keil E, Schulze-Osthoff K, Schmitz l: Up-regulation of c-FLIP short by NFAT contributes to apoptosis resistance of short-term activated T cells. Blood 2008, 112:690-698.

83. Jessen R: Nfatc-genes as target of insertional mutagenesis in retrovirusinduclymphomas. PhD Thesis Aarhus University 2011.

84. Glud SZ, Sorensen AB, Andrulis M, Wang B, Kondo E, Jessen R, Krenacs L,

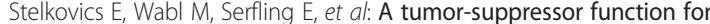
NFATc3 in T-cell lymphomagenesis by murine leukemia virus. Blood 2005, 106:3546-3552.

85. Uren AG, Kool J, Matentzoglu K, de Ridder J, Mattison J, van Uitert M, Lagcher W, Sie D, Tanger E, Cox T, et al: Large-scale mutagenesis in p19 (ARF)- and p53-deficient mice identifies cancer genes and their collaborative networks. Cell 2008, 133:727-741.

86. Hansen GM, Skapura D, Justice MJ: Genetic profile of insertion mutations in mouse leukemias and lymphomas. Genome Res 2000, 10:237-243.

87. Suzuki T, Shen H, Akagi K, Morse HC, Malley JD, Naiman DQ, Jenkins NA Copeland NG: New genes involved in cancer identified by retroviral tagging. Nat Genet 2002, 32:166-174

88. Retroviral tagged cancer gene database: RTCGD; 2011. Online: http://rtcdg. ncifcrf.gov/.

89. Ranger AM, Gerstenfeld LC, Wang J, Kon T, Bae H, Gravallese EM, Glimcher MJ, Glimcher LH: The nuclear factor of activated T cells (NFAT) transcription factor NFATp (NFATc2) is a repressor of chondrogenesis. J Exp Med 2000, 191:9-22.

90. Robbs BK, Cruz AL, Werneck MB, Mognol GP, Viola JP: Dual roles for NFAT transcription factor genes as oncogenes and tumor suppressors. Mol Cell Biol 2008, 28:7168-7181.

91. Mancini $M$, Toker A: NFAT proteins: emerging roles in cancer progression. Nat Rev Cancer 2009, 9:810-820.

92. Muller MR, Rao A: NFAT, immunity and cancer: a transcription factor comes of age. Nat Rev Immunol 2010, 10:645-656.

93. Pham LV, Tamayo AT, Li C, Bueso-Ramos C, Ford RJ: An epigenetic chromatin remodeling role for NFATc1 in transcriptional regulation of growth and survival genes in diffuse large B-cell lymphomas. Blood 2010, 116:3899-3906.

94. Buchholz M, Schatz A, Wagner M, Michl P, Linhart T, Adler G, Gress TM, Ellenrieder $\mathrm{V}$ : Overexpression of c-myc in pancreatic cancer caused by ectopic activation of NFATC1 and the Ca2+/calcineurin signaling pathway. EMBO J 2006, 25:3714-3724.

95. Koenig A, Linhart T, Schlengemann K, Reutlinger K, Wegele J, Adler G, Singh G, Hofmann L, Kunsch S, Buch T, et al: NFAT-induced histone acetylation relay switch promotes c-Myc-dependent growth in pancreatic cancer cells. Gastroenterology 2010, 138:e1181-1182.

96. Avots A, Buttmann M, Chuvpilo S, Escher C, Smola U, Bannister AJ, Rapp UR, Kouzarides T, Serfling E: CBP/p300 integrates Raf/Rac-signaling pathways in the transcriptional induction of NF-ATc during T cell activation. Immunity 1999, 10:515-524.

97. Terui Y, Saad N, Jia S, McKeon F, Yuan J: Dual role of sumoylation in the nuclear localization and transcriptional activation of NFAT1. J Biol Chem 2004, 279:28257-28265.

98. Samanta DN, Palmetshofer A, Marinkovic D, Wirth T, Serfling E, Nitschke L: $B$ cell hyperresponsiveness and expansion of mature follicular $B$ cells but not of marginal zone B cells in NFATc2/c3 double-deficient mice. J Immunol 2005, 174:4797-4802.

doi:10.1186/1478-811X-10-16

Cite this article as: Serfling et al: NFATc1/aA: The other Face of NFAT

Factors in Lymphocytes. Cell Communication and Signaling 2012 10:16.

\section{Submit your next manuscript to BioMed Central and take full advantage of:}

- Convenient online submission

- Thorough peer review

- No space constraints or color figure charges

- Immediate publication on acceptance

- Inclusion in PubMed, CAS, Scopus and Google Scholar

- Research which is freely available for redistribution 